\title{
Our Commitment to Diversity, Equity, and Inclusion
}

"A diverse mix of voices leads to better discussions, decisions, and outcomes for everyone." - Sundar Pichai, CEO of Google

The past few months have included a lot of reflection, learning, and action planning for me personally, and as Editor-in-Chief of the Journal of Sport Rehabilitation (JSR). During this time, I re-read the editorial I wrote, "Opportunity Awaits,"1 as I transitioned into the role. Many of the priorities identified still ring very true to me now, but more deeply and with more necessity. I continually return to the initial question I posed: "What does it mean to be a multidisciplinary journal for sport rehabilitation?"

I have been acutely aware of and affected by the inexcusable, racially motivated actions that led to the death of George Floyd and so many other Black lives. My heart is heavy. I am sure many readers can relate to the myriad sentiments I have expressed, including grief, a clearer understanding of my own privilege, and a re-ignited motivation and call to be a change agent against systemic inequalities and racism. The uprisings and calls for anti-racist action have provided clarity on how to more fully and appropriately answer, "What does it mean to be a multidisciplinary journal for sport rehabilitation?" The JSR Editorial Board is committing to bring about positive change to the journal that recognizes and celebrates the research and perspectives of persons of color. As clinicians, we serve everyone, and so every person should feel welcomed into our scholarly community.

I want to acknowledge and affirm the statement of Skip Maier, ${ }^{2}$ CEO of Human Kinetics (publisher of JSR), which denounces racial intolerance and commits to help "repair the damage of systematic racism." The JSR Editorial Board is joining forces to promote positive change within JSR through purposeful diversity, equity, and inclusion initiatives. To this point, we are moving beyond acknowledging inequities and are actively working to develop initiatives to better create and sustain a journal that you can rely upon to recognize and publish evidence that can be translated to the diverse patient populations we serve. Specific goals will focus on 1) addressing disparities between the editorial board and JSR's diverse authorship and readership, and 2) promoting and supporting cultural proficiency in sport rehabilitation research from diverse groups at all levels (e.g., authors, peer reviewers, editorial board members). We are actively taking the first steps together knowing that this will be a long-term process that will not stop.

Together, we will work diligently to maintain a culture that embraces diversity, equity, and inclusion to ensure long-term success and impact as an international journal that advances the understanding of sport rehabilitation to improve patient care. That is what it means to be a multidisciplinary journal.

Kellie C. Huxel Bliven, PhD, ATC, A.T. Still University, JSR Editor in Chief

\section{References}

1. Huxel Bliven KC. Opportunity Awaits ... J Sport Rehabil. 2019;28(5):1. PubMed ID: 31170871 doi:10.1123/jsr.2019-0188

2. Statement from Skip Maier, CEO of Human Kinetics. June 8, 2020. https://us.humankinetics.com/blogs/articles/statement-from-skip-maierceo-of-human-kinetics. Accessed July 12, 2020. 